\title{
Level of Access and Competition in Broadband Markets
}

\section{Citation}

Bourreau, Marc, and Pinar Dogan. 2010. Level of Access and Competition in Broadband Markets. HKS Faculty Research Working Paper Series, RWP10-006, John F. Kennedy School of Government, Harvard University.

\section{Published Version}

http://web.hks.harvard.edu/publications/workingpapers/citation.aspx?Publd=7105

\section{Permanent link}

http://nrs.harvard.edu/urn-3:HUL.InstRepos:4454152

\section{Terms of Use}

This article was downloaded from Harvard University's DASH repository, and is made available under the terms and conditions applicable to Other Posted Material, as set forth at http:// nrs.harvard.edu/urn-3:HUL.InstRepos:dash.current.terms-of-use\#LAA

\section{Share Your Story}

The Harvard community has made this article openly available.

Please share how this access benefits you. Submit a story.

Accessibility 


\title{
Level of Access and Competition in Broadband Markets Faculty Research Working Paper Series
}

\author{
Marc Bourreau
}

Institut Telecom and CREST-LEI

\section{Pinar Dogan}

Harvard Kennedy School

\section{February 2010 RWP10-006}

The views expressed in the HKS Faculty Research Working Paper Series are those of the author(s) and do not necessarily reflect those of the John F. Kennedy School of Government or of Harvard University. Faculty Research Working Papers have not undergone formal review and approval. Such papers are included in this series to elicit feedback and to encourage debate on important public policy challenges. Copyright belongs to the author(s). Papers may be downloaded for personal use only. 


\title{
Level of Access and Competition in Broadband Markets*
}

\author{
Marc Bourreau ${ }^{\dagger}$ and Pınar Doğan
}

February, 2010

\begin{abstract}
In this paper, we consider an unregulated incumbent who owns a broadband infrastructure and decides on how much access to provide to a potential entrant. The level of access, i.e., the network elements that are shared in the provision of competing broadband services, not only determines the amount of investment the entrant needs to undertake to enter the market, but also the intensity of post-entry competition. We consider an access scheme that determines an access level and an associated two-part tariff. We show that the equilibrium level of access is higher when the sensitivity of product differentiation to the level of access is lower, and when the marginal investment cost is higher. We also show that the unregulated incumbent sets a suboptimally low (high) level of access if the degree of service differentiation is sufficiently high (low).
\end{abstract}

Keywords: Infrastructure Sharing; Access; Telecommunications.

\section{Introduction}

Regulation of access is crucial for fostering competition in the broadband market; the incumbent firms are the monopolist providers of an essential input-access to network elements, including the

\footnotetext{
${ }^{*}$ Financial support from France Telecom is gratefully acknowledged. We also thank Katie Naeve for her editorial assistance.

${ }^{\dagger}$ Institut Telecom, Telecom ParisTech, Paris, France, and CREST-LEI. E-mail: marc.bourreau@telecomparistech.fr.

${ }^{\ddagger}$ Harvard Kennedy School, Harvard University. E-mail: pinar_dogan@hks.harvard.edu.
} 
local loop-and are by and large vertically integrated to the downstream market. Regulating oneway access involves determining (i) the mandatory access level (i.e., the network elements that are subject to mandatory access), and (ii) the access price scheme.

The latter task-determining the optimal access price for a given level of access-has received a great deal of attention both in the theoretical literature and in the policy arena. ${ }^{1}$ More recently, a number of studies have focused on the effect of access prices on the incumbent firms' incentives to invest, ${ }^{2}$ while a number of others have focused on its potential effect on build-or-buy decisions of the entrant firms. ${ }^{3}$ A series of complementing studies look at the empirical relationship between access obligations (or access prices) and investment in the broadband market. ${ }^{4}$

In contrast with the regulation of access prices, the theoretical literature provides little guidance to regulation of the access level, despite its highlighted importance in the "ladder of investment" approach introduced by Cave (2006), which has been embraced by many national regulatory authorities. According to this approach, regulation of the access level (as well as access prices) can play a fundamental role in shaping competition in the longer-term: setting the access level "right" can promote facility-based competition, which is often viewed as the ultimate aim in the broadband sector. ${ }^{5}$ Note that, however, regulation of the access level is critical even in the absence of any dynamic efficiency concerns due to its shorter-term impact on competition, i.e., static efficiency.

In this paper, we focus on the impact of the level of access on competition in the broadband market. More specifically, we compare an unregulated incumbent's incentives for infrastructure sharing with the social optimum in the absence of any dynamic efficiency concerns.

We consider an unregulated incumbent who sets the level of access to its broadband infrastructure for a potential entrant, who initially does not own any network infrastructure. The incumbent can provide access to its network at several different levels. At the one extreme, the incumbent can refuse provide access to its infrastructure, which leaves full network duplication as the only means of entry into the market. At the other extreme, the entrant can rely solely on the incumbent's infrastructure to provide its services. For example, a pure resale arrangement requires full access

\footnotetext{
${ }^{1}$ See Vogelsang (2003), Armstrong (2002), and Laffont and Tirole (2000) for comprehensive reviews on access pricing policies in the telecommunications industry.

${ }^{2}$ See, for example, Jorde et al. (2000) and Vareda (2007).

${ }^{3}$ See, for example, Bourreau and Doğan (2005) and (2006), Sappington (2006), Gayle and Weisman (2007), and Avenali et al (2010).

${ }^{4}$ See, for example, Crandall et al. (2004), Waverman et al. (2007), Friederiszick et al (2008), and Wallsten and Hausladen (2009). Also, see Cambini and Jiang (2009) for a review of both theoretical and empirical literature on access regulation and investment in broadband markets.

${ }^{5}$ See Bourreau et al (2009) for a critical review of the ladder of investment approach.
} 
to the incumbent's infrastructure. In between these two extreme cases, access to network elements is possible at several different levels and we consider a continuum of them. ${ }^{6}$ A lower level of access to the infrastructure refers to fewer network elements that are shared between the incumbent and the entrant. In the ladder of investment jargon, this is a higher "rung" on the investment ladder, as it requires a heavy investment for the entrant.

Several economic factors are likely to impact an unregulated incumbent's decision on the level of access it provides to the entrant firms. ${ }^{7}$ Those we explicitly consider in this paper are: the economic feasibility of bypass; the cost of investing in different network elements; the efficiency of the entrant firm in providing broadband services; the intensity of potential competition (and how it varies at different levels of access).

We assume that different levels of access not only require the entrant to undertake different levels of investment, but also may lead to different intensities in post-entry competition. More specifically, we assume that a higher (lower) level of access-that is, more (less) infrastructure sharing-leads to a lower (higher) degree of differentiation in broadband services.

We show that the equilibrium level of access is higher when the sensitivity of product differentiation to the level of access is lower, and when the marginal investment cost is higher. We also show that the unregulated incumbent sets a suboptimally low (high) level of access if the degree of service differentiation is sufficiently high (low).

The paper is organized as follows. In Section 2, we lay out our benchmark model in an unregulated environment where the full by-pass of the incumbent's infrastructure is economically viable. In Section 3, we characterize the equilibrium access scheme, and we compare it with the social optimum in Section 4. In Section 5, we extend our basic model in various directions and discuss the validity of our results (i) in the absence of a full-bypass option, (ii) with asymmetric firms (in terms of efficiency in providing broadband services), (iii) with different modes of competition (Cournot versus Bertrand competition), and (iv) with multiple entrants in a regulated environment. Then, we conclude.

\footnotetext{
${ }^{6}$ See, for example, Cave (2006) who ranks the network elements for broadband access with the order of relative replicability-the copper loop, DSLAMs, backhaul, core IP network, access to the web, and resale.

${ }^{7}$ There may also be some technological or technical constraints, which we do not consider in this paper.
} 


\section{The Benchmark Model}

We consider an unregulated incumbent (Firm 1) and a potential entrant (Firm 2). The incumbent's broadband infrastructure is composed of a continuum of network elements.

The incumbent decides to provide access to $\alpha \in[0,1]$ network elements of its infrastructure to the potential entrant. We will refer to $\alpha$ as the level of access. If $\alpha=0$, the incumbent denies access to its infrastructure and the entrant's sole possibility to enter in the market is by building its own infrastructure.

If $\alpha=1$, the incumbent provides full access (i.e., resale of broadband services). Any intermediary level of $\alpha \in(0,1)$ refers to an access arrangement with which the incumbent provides access to some-but not all-network elements. ${ }^{8}$ If the entrant obtains access at a level $\alpha$ of the incumbent's infrastructure, it builds the remaining $(1-\alpha)$ network elements that are necessary to provide broadband services.

We assume that the marginal cost of providing access at any level is constant, and we normalize it to zero.

Consumers Following Dixit (1979) and Singh and Vives (1984), we consider a representative consumer with a utility function

$$
U\left(q_{1}, q_{2}\right)=a q_{1}+a q_{2}-\frac{1}{2}\left[\left(q_{1}\right)^{2}+\left(q_{2}\right)^{2}+2(1-s) q_{1} q_{2}\right]
$$

where $q_{1}$ and $q_{2}$ denote the quantity of the incumbent and the entrant, respectively, and $s$ denotes the degree of service differentiation, with $s \in[\underline{s}, \bar{s}], \underline{s} \in[0, \bar{s})$ and $\bar{s} \leq 1$. The inverse demand is then

$$
p_{i}=a-q_{i}-(1-s) q_{j}
$$

where $p_{i}$ denotes the price of firm $i$, with $i, j=1,2$ and $i \neq j$.

Service differentiation The degree of service differentiation depends on the level of access, i.e., $s=s(\alpha)$. We assume that $s(1)=\underline{s}$ and $s(0)=\bar{s}$, and that $\partial s(\alpha) / \partial \alpha<0$, that is, the degree of service differentiation decreases with the level of access to the incumbent's infrastructure.

\footnotetext{
${ }^{8}$ This is in line with Guthrie (2006), who argues that between the two extreme cases -pure service-based competition and pure facility-based competition-there is a continuum of cases in which the entrant relies on the incumbent's infrastructure.
} 
This is a key assumption in our model: once the level of access is set, the degree of differentiation is determined exogenously. In reality, firms can invest in service differentiation for any given level of access. However, at least in some cases such investments are limited by the access structure. For example, entrant firms can provide television services over DSL if they have an ULL access (relatively low $\alpha$ ), whereas they might not be able to do so if they have a bitstream access (relatively high $\alpha$ ). Also, entrant firms cannot provide some services-such as VoIP-if they have a pure DSL resale arrangement with the incumbent $(\alpha=1)$.

Cost of entry If the incumbent provides access to its infrastructure at a level $\alpha$, it sets an access tariff, $T=r q_{2}+f$, where $r \geq 0$ and $f \geq 0$ denote the per-unit access price and the fixed access fee, respectively. The access tariff may take three forms: a fixed fee $(r=0, f>0)$, a linear tariff $(r>0, f=0)$, or a two-part tariff $(r>0, f>0)$.

If the entrant obtains access from the incumbent, it pays $T$ and invests in the remaining network elements, which entails a cost denoted by $d(\alpha)$. We assume that $\partial d / \partial \alpha<0$, that is, the higher the level of access, the lower the investment required to provide broadband services. ${ }^{9}$

In the broadband market, this assumption translates to the following. The level of investment the entrant needs to undertake to enter the broadband market is the highest when it builds its own infrastructure $(\alpha=0)$, and it is the lowest when it solely relies on the incumbent's infrastructure to provide its services, e.g., with a pure resale arrangement $(\alpha=1)$. Entry with bitstream access, which implies $\alpha<1$ in our setting, involves a higher entry cost (as it requires an investment in an IP network) than entry with a pure resale arrangement, whereas entry with an access to the unbundled local loop is more costly than entry with bitstream access (as it requires the entrant to install its own DSLAMs on top of an IP network).

If the entrant decides to build its own infrastructure, it invests $d(0)$. Notice that we do not assume any economies or diseconomies of scope in investing in network elements; ${ }^{10}$ the cost of building the initial $\alpha$ network elements, $(d(0)-d(\alpha))$, plus the cost of building the remaining network elements, $d(\alpha)$, is equal to the cost of building the entire infrastructure, $d(0)$.

We also assume profit and welfare functions are concave in $\alpha$.

Below, we list the remaining assumptions of our benchmark model, each of which are relaxed

\footnotetext{
${ }^{9}$ This is consistent with the "Ladder of Investment" approach introduced by Martin Cave. See for example, Cave (2006).

${ }^{10}$ Our informal exchange with an incumbent operator confirms that there are no significant economies of scope in investing in broadband network elements.
} 
in Section 5:

i. full-bypass of the incumbent's network is economically feasible,

ii. for any given level of access, the incumbent and the entrant firms have a symmetric marginal cost of providing broadband services, $c$, and

iii. firms compete with prices.

In Section 5 we also study the case with multiple entrants in a regulated environment.

The timing The timing of the game is as follows. The incumbent decides on the access scheme $\{\alpha, T\}$, that is, it sets the access level, $\alpha$, and the access tariff, $T .^{11}$ Then, the entrant decides whether or not to obtain access to the incumbent's infrastructure. If the entrant obtains access, it invests in the remaining network elements, $(1-\alpha)$, necessary for providing broadband services. If it does not obtain any access, it invests $d(0)$ and builds its own infrastructure. Finally, firms compete, and profits are realized.

\section{Equilibrium}

We look for the subgame perfect equilibrium of this game, and hence, start with the last stage of the game and proceed backwards.

Competition (Stage 3) Let $\Pi_{i}$ denote the profit of firm $i$, with $i=1,2$, when the entrant obtains access with the scheme $\{\alpha, T\}$. In equilibrium, the incumbent and the entrant obtain $\Pi_{1}(\alpha, r, f)=\pi_{1}(s(\alpha), r)+f$ and $\Pi_{2}(\alpha, r, f)=\pi_{2}(s(\alpha), r)-f$, respectively, where the expressions for $\pi_{1}$ and $\pi_{2}$ can be found in Appendix A.

Let $\bar{\Pi}_{i}$ denote the profit of firm $i$, when there is full-bypass. Then, firms obtain $\bar{\Pi}_{1}=\pi(\bar{s})$ and $\bar{\Pi}_{2}=\pi(\bar{s})-d(0)$, with

$$
\pi(\bar{s})=\frac{(a-c)^{2} \bar{s}}{(2-\bar{s})(1+\bar{s})^{2}} .
$$

Full-bypass is viable if and only if $\bar{\Pi}_{2} \geq 0$, which we assume is the case in the benchmark model.

\footnotetext{
${ }^{11}$ Note that, at this initial stage, the incumbent decides whether or not to provide any access, since it can decide to set $\alpha=0$, i.e., refuse to deal with the entrant.
} 
Entrant's decision to obtain access (Stage 2) The entrant obtains access if and only if $\Pi_{2}(\alpha, r, f) \geq \bar{\Pi}_{2}$, which can be rewritten as $f \leq \Phi(r)$, with

$$
\Phi(r)=\pi_{2}(s(\alpha), r)-d(\alpha)-(\pi(\bar{s})-d(0)) .
$$

Equilibrium access scheme $\{\alpha, T\}$ (Stage 1) We first determine the optimal access tariff $T$ for a given $\alpha$, and then, determine the optimal $\alpha$ for the incumbent.

For a given $\alpha$, the problem of the incumbent is:

$$
\max _{r, f} \Pi_{1}(\alpha, r, f)=\max _{r, f}\left\{\pi_{1}(s(\alpha), r)+f\right\}
$$

subject to

$$
f \leq \Phi(r)
$$

and

$$
f \geq 0
$$

The first constraint puts an upper bound to the per-unit access price, whereas the second excludes subsidized entry. We find that $\pi_{2}(s(\alpha), r)$ is strictly decreasing with $r$, and that there exists a unique $\bar{r}(\alpha)$ such that $\Phi(\bar{r})=0$, and such that for all $r>\bar{r}(\alpha)$ we have $\Phi(r)<0$. That is, if $r>\bar{r}(\alpha)$, the constraints $(\mathrm{C} 1)$ and $(\mathrm{C} 2)$ cannot be satisfied simultaneously. We find that

$$
\bar{r}(\alpha)=\frac{(a-c)(3-s(\alpha))}{2(2-s(\alpha))}-\frac{(3-s(\alpha))(1+s(\alpha)) \sqrt{d(\alpha)+(\pi(\bar{s})-d(0))}}{2 \sqrt{s(\alpha)(2-s(\alpha))}} .
$$

The first term represents the threshold unit access charge above which $q_{2}<0$, which implies that for all $r<\bar{r}(\alpha)$, we have $q_{2}>0$ as the second term is positive.

Let $\widehat{r}(\alpha)$ denote the unconstrained per-unit access price, that is, the per-unit access price that maximizes $\Pi_{1}(\alpha, r, f)$ when $(\mathrm{C} 1)$ is binding. We find that

$$
\widehat{r}(\alpha)=\frac{(a-c)(1-s(\alpha))(3-s(\alpha))^{2}}{2\left(9-10 s(\alpha)+5(s(\alpha))^{2}\right)} .
$$

Note that $\widehat{r}$ can be either higher or lower than $\bar{r}$; therefore, the incumbent may not be able to charge $\widehat{r}$ in equilibrium. If $\widehat{r}>\bar{r}$, then the incumbent sets $\bar{r}$ as the per-unit access price and $f=0$.

Finally, let $V$ denote for value of full-bypass to the entrant, i.e., $V=\pi(\bar{s})-d(0)$. The following 
Proposition characterizes the equilibrium access tariff.

Proposition 1 For a given level of access $\alpha \in[0,1]$, if $s(\alpha)=1$, then $T^{*}=f^{*}$, with $f^{*}=\Phi(0)$, and if $s(\alpha)<1$, then

(i) $T^{*}=r^{*} q_{2}+f^{*}$, with $r^{*}=\widehat{r}$, and $f^{*}=\Phi(\widehat{r})$, if $V$ is sufficiently low, and

(ii) $T^{*}=r^{*} q_{2}$, with $r^{*}=\bar{r}$, otherwise.

Proof. See Appendix B.

For a given level of access, if the demand for the services of the incumbent and the entrant are independent (i.e., $s(\alpha)=1$ ), the equilibrium access tariff is characterized with a fixed fee. That is, the incumbent sets a zero per-unit price to maximize the entrant's gross profit, and extracts it with the appropriate fixed fee. ${ }^{12}$

If the demand for services of the two firms are not independent (i.e., $s(\alpha)<1$ ), depending on the value of the full-bypass, $V$, the equilibrium access tariff can be either a linear, or a two-part tariff. When the value of full-bypass is sufficiently high, we have $\widehat{r}>\bar{r}(\alpha)$, which means that the incumbent cannot set $\widehat{r}$ and simultaneously satisfy constraints (C1) and (C2). The equilibrium access tariff is, hence, linear. Otherwise, the equilibrium tariff has two-parts. Since the equilibrium access tariff can take one of the two forms, below we discuss the properties of each of them separately.

\section{Two-part access tariff in equilibrium}

If the value of full bypass, $V$, is sufficiently low, then the equilibrium tariff is characterized with a two-part tariff; $T^{*}=r^{*} q_{2}+f^{*}$, with $r^{*}=\widehat{r}$. A per-unit access price increases the perceived marginal cost of the entrant and therefore enables the incumbent to compete less aggressively.

Lemma 1 When the equilibrium is characterized with a two-part tariff, the per-unit access price is increasing with the level of access.

Proof. We have $\partial \widehat{r} / \partial s<0$, and hence, $\partial \widehat{r} / \partial \alpha>0$ for all $\alpha$.

If the value of full-bypass is sufficiently low, the per-unit access price is higher for a higher level of access. Note that this result neither relates to the investment cost of the entrant, $d(\alpha)$,

\footnotetext{
${ }^{12}$ Note that, this is unlikely to be the case in the broadband market, where the services provided by different firms are viewed as substitutes at least to some extent. Therefore, we will not consider this special case is the remaining of this paper.
} 
as it is internalized through the fixed fee, nor does it relate to the marginal cost of access, which is normalized to zero. The access price is increasing with $\alpha$ for purely strategic reasons, and not for cost reasons: the per-unit price serves as a means to soften competition, and the intensity of competition depends on the level of access since it determines the degree of differentiation. If the level of access is high (low), differentiation in services is low (high), and the incumbent's opportunity cost of expanding its retail sales is high (low) as the competing services are viewed as strong substitutes by the consumers.

\section{Linear access tariff in equilibrium}

If the value of full bypass, $V$, is sufficiently high, the incumbent sets a linear access price, $T^{*}=r^{*} q_{2}$, with $r^{*}=\bar{r}$.

Lemma 2 When the equilibrium is characterized with a linear tariff, the per-unit access price can increase or decrease with the level of access.

Proof. We have

$$
\begin{aligned}
\frac{\partial \bar{r}}{\partial \alpha}= & {\left[\frac{a-c}{2(2-s)^{2}}+\frac{(1-s)\left(s^{2}-2 s+3\right) \sqrt{\pi(\bar{s})-d(0)+d(\alpha)}}{(s(2-s))^{3 / 2}}\right] \frac{\partial s}{\partial \alpha} } \\
& +\left[-\frac{(1+s)(3-s)}{4 \sqrt{\pi(\bar{s})-d(0)+d(\alpha)} \sqrt{s(2-s)}}\right] \frac{\partial d}{\partial \alpha} .
\end{aligned}
$$

The first term is negative as the term in brackets is positive and $\partial s / \partial \alpha \leq 0$, whereas the second term is positive as the term in brackets is negative and $\partial d / \partial \alpha \leq 0$. Therefore, $\bar{r}(\alpha)$ can either increase or decrease with $\alpha$. If $\partial s / \partial \alpha$ is small in absolute terms, then $\bar{r}(\alpha)$ tends to increase with $\alpha$. Whereas, if $\partial d / \partial \alpha$ is small in absolute terms, then $\bar{r}(\alpha)$ tends to decrease with $\alpha$.

If the value of full-bypass is sufficiently high, then the equilibrium tariff does not have a fixed component, which means that the incumbent cannot fully internalize the impact of the level of access on the development cost. The level of access affects the linear access price in the following way: a marginal increase in the level of access implies a lower development cost for the entrant, which in turn lowers the rents the incumbent needs to give away to ensure that the entrant does not opt for full-bypass. Since in the absence of a fixed component these rents are purely determined by the per-unit access price, this implies a higher per-unit access price in equilibrium.

On the other hand, a higher level of access implies a more intense competition due to a lower degree of differentiation. For this reason, everything else equal, full-bypass becomes a relatively 
more attractive option to the entrant, which means that the incumbent needs to give up some rents (to keep the entrant relying on its infrastructure) by charging a lower per-unit access price. Note that the impact of the level of access on the per-unit access price we have discussed under the two-part tariff is also present in this case. However, it is dominated by the former effect.

\section{The equilibrium level of access}

The optimal level of access is defined by

$$
\alpha^{*}=\arg \max _{\alpha \in[0,1]} \Pi_{1}\left(\alpha, r^{*}(\alpha), f^{*}(\alpha)\right)
$$

Since the value of the outside option determines the structure of the access tariff, which in turn affects the equilibrium access level, we discuss the two cases-equilibrium with a two-part tariff and equilibrium with a linear tariff-separately.

First, consider the case where the value of full-bypass is sufficiently low so that the equilibrium access schedule is a two-part tariff and that the equilibrium unit price is characterized by $\widehat{r}$. Then, assuming an interior solution, the first-order condition of the incumbent's problem can be written as

$$
\frac{\partial\left(\pi_{1}+\pi_{2}\right)}{\partial s} \frac{\partial s}{\partial \alpha}-\frac{\partial d}{\partial \alpha}=0
$$

The level of access has two opposite effects on the industry profits. The first term in equation (1) is negative as a higher level of access implies a lower degree of differentiation, which hurts industry profits. A higher "market value" (a higher $a-c$ ) implies that this first term is higher in absolute terms (as the industry profits are increasing with the market value), and hence, the equilibrium access level tends to be lower. The second term corresponds to the marginal investment cost, and it is positive since $\partial d / \partial \alpha<0$. Therefore, a higher marginal investment cost, $\partial d / \partial \alpha$, in absolute terms, leads the incumbent to set a higher level of access. In other words, if the entrant's investment cost exhibits a greater sensitivity to the level of access, then the equilibrium level of access tends to be high, simply because the incumbent has to compensate the entrant for its investment cost by charging a lower fixed fee.

The following Proposition summarizes these findings.

Proposition 2 The equilibrium level of access is higher when

(i) the sensitivity of product differentiation to the level of access $(|\partial s / \partial \alpha|)$ is lower, and 
(ii) the marginal investment cost $(|\partial d / \partial \alpha|)$ is higher.

Proof. Immediate from equation (1) and our assumption on concavity.

Now, consider the case where the value of the full-bypass is sufficiently high so that the equilibrium access schedule is a linear tariff and that the equilibrium unit price is characterized by $\bar{r}$. Then, the first-order condition can be written as

$$
\frac{\partial \pi_{1}}{\partial s} \frac{\partial s}{\partial \alpha}+\frac{\partial \pi_{1}}{\partial r}\left(\frac{\partial \bar{r}}{\partial s} \frac{\partial s}{\partial \alpha}+\frac{\partial \bar{r}}{\partial d} \frac{\partial d}{\partial \alpha}\right)=0
$$

One can show that $\pi_{1}$ has an inverted U-shape with respect to $s$; it increases with low values of $s$ and then decreases with higher values of $s$. Therefore, the first term can either be negative or positive. One can also show that the second term can be either negative or positive. This is because as Lemma 2 shows, the term in parenthesis can either be negative or positive, and this is also true for $\partial \pi_{1} / \partial r$.

Since it is not possible to characterize the equilibrium level of access in this case, we now revert to numerical simulations.

\section{A numerical example}

We adopt the following functional form for the differentiation function $s(\alpha)=\alpha \underline{s}+(1-\alpha) \bar{s}$, which satisfies our assumption $\partial s(\alpha) / \partial \alpha<0$. We assume that $d(\alpha)=\delta\left(1-\alpha^{1 / 2}\right)$, which implies that the development cost decreases with the level of access. We set $a=2$ and $c=0$.

We run our simulations for $\{\underline{s}, \bar{s}\} \in\{0.1,0.2, \ldots, 0.6\} \times\{\underline{s}+0.1, \underline{s}+0.2 \ldots, 0.9\}$ and $\delta \in$ $\{0,0.01, \ldots, \Pi(1)\}$. Note that, within this parameter range, full-bypass can be a viable option or not. ${ }^{13}$ Also, the equilibrium tariff structure is linear for 80 per cent of the cases, when full-bypass is viable. Our simulations show that the findings of Proposition 2 hold when the equilibrium tariff is linear. That is, the equilibrium access level is higher when the sensitivity of product differentiation to the level of access is lower, and when the marginal investment cost is higher. ${ }^{14}$

\footnotetext{
${ }^{13}$ In 62 per cent of the cases, full-bypass is viable.

${ }^{14}$ We have $|\partial s / \partial \alpha|=\bar{s}-\underline{s}$ and $|\partial d / \partial \alpha|$ increasing with $\delta$. In order to verify part (i) of Proposition 2 , we fix $\underline{s}$, and test if a marginal increase in $\bar{s}$ (by a step of 0.01 ) leads to an increase in $\alpha^{*}$. To verify part (ii), we test whether a marginal increase in $\delta$ (by a step of 0.01 ) leads to an increase in $\alpha^{*}$.
} 


\section{Socially optimal level of access}

In this section, we assume that both the access price and the access level is subject to regulation, and we characterize the socially optimal access schedule.

The social welfare is defined as the sum of industry profits and consumer surplus. Let $w=C S+$ $\pi_{1}+\pi_{2}$, where $C S$ denotes the consumer surplus, which is given by $C S=\left(\left(q_{1}\right)^{2}+\left(q_{2}\right)^{2}+2(1-s)\right) / 2$. The social welfare is then given by $W=w-d(\alpha)$.

Let $\alpha^{w}$ and $T^{w}=r^{w} q_{2}+f^{w}$ denote the socially optimal access level and tariff, respectively. Note that the fixed fee, $f$, has a neutral effect on social welfare, as it is a pure transfer from the entrant to the incumbent.

Lemma 3 For a given $\alpha$, the optimal access tariff is characterized by a zero per-unit access price.

Proof. We have

$$
\frac{\partial^{2} W}{\partial r^{2}}=\frac{-\left(5 s^{2}-10 s+9\right)}{(3-s)^{2}(1+s)^{2}}<0
$$

for all $s$, and

$$
\left.\frac{\partial W}{\partial r}\right|_{r=0}=\frac{-(3-s)^{2}(a-c)}{\left(5 s^{2}-10 s+9\right)}<0
$$

therefore, $W$ is decreasing with $r$ which implies that the optimal per-unit price is $r^{w}=0$.

Given that $r^{w}=0$, the regulator chooses $\alpha$ so as to maximize $w(s(\alpha), 0)-d(\alpha)$. In comparing the socially optimal level of access with the equilibrium level of access in the unregulated environment, we focus our attention to the range of parameters for which the equilibrium tariff schedule is two-part, i.e., $T^{*}=\widehat{r}(\alpha) q_{2}+\Phi(\widehat{r})$. To study the case when the equilibrium tariff is linear, i.e., $T^{*}=\bar{r}(\alpha) q_{2}$, we revert to numerical simulations as it is not possible to provide analytical results.

The problem of the incumbent is to choose $\alpha$ so as to maximize $\pi_{1}\left(s(\alpha), r^{*}(s(\alpha))\right)+\pi_{2}\left(s(\alpha), r^{*}(s(\alpha))\right)-$ $d(\alpha)$. Given our assumption on concavity of $W$ and $\Pi_{1}$, the incumbent sets too low an $\alpha$ if

$$
\frac{\partial\left(\pi_{1}\left(s(\alpha), r^{*}(s(\alpha))\right)+\pi_{2}\left(s(\alpha), r^{*}(s(\alpha))\right)\right)}{\partial \alpha}<\frac{\partial w}{\partial \alpha}
$$

and too high an $\alpha$ otherwise. This condition is equivalent to

$$
\frac{\partial\left(\pi_{1}\left(s, r^{*}(s)\right)+\pi_{2}\left(s, r^{*}(s)\right)\right)}{\partial s}>\frac{\partial w}{\partial s},
$$

given that $\partial s / \partial \alpha<0$. 
Proposition 3 The equilibrium level of access is suboptimally low if $s\left(\alpha^{*}\right)$ is sufficiently high, and suboptimally high otherwise.

\section{Proof. See Appendix C.}

We find that $\alpha^{*}<\alpha^{w}$ if $s\left(\alpha^{*}\right)>0.306$ and $\alpha^{*} \geq \alpha^{w}$ otherwise. ${ }^{15}$ If $s\left(\alpha^{*}\right)$ is sufficiently high, then by offering a lower level of access, an unregulated incumbent limits the adverse effect of a lower degree of differentiation on its profit. Otherwise, it prefers to set a higher level of access that enables it to extract a higher rent from the entrant.

For the cases in which the equilibrium tariff is linear, we cannot provide analytical results. However, using the specifications provided in Section 3, we ran simulations and verified that the equilibrium level of access is suboptimally low for high values of $s\left(\alpha^{*}\right)$, and is suboptimally high otherwise. ${ }^{16}$

\section{Extensions}

In this section we discuss how our main results are modified when we relax some of the assumptions we have made in the benchmark model.

\subsection{No full-bypass option for the entrant}

The major policy justification for access regulation is that competition may not viable without the entrants' access to the incumbent's infrastructure in reasonable terms, and that an unregulated incumbent may not have incentives to open its infrastructure to its competitors in the absence of regulation. The implicit assumption is that pure facility-based competition (i.e., full-bypass) is economically not feasible, or is very limited. In this paper, we assumed that full-bypass was indeed an option-yet an expensive one-for the entrant (i.e., $\bar{\Pi}_{2} \geq 0$ ), and studied the incumbent's incentives when it sets the access scheme and showed that the equilibrium per-unit access charge is either $\widehat{r}$ or $\bar{r}$ in this case.

Let $\overline{\bar{r}}$ denote the threshold per-unit access charge, above which $\pi_{2}(s(\alpha), r)-d(\alpha)$ is negative. Since $\bar{r}$ represents the same threshold for $\pi_{2}(s(\alpha), r)-d(\alpha)-V$, and since $\partial \pi_{2}(s(\alpha), r) / \partial r<0$, we have $\overline{\bar{r}} \geq \bar{r}$. Similarly to our benchmark analysis, one can show that when full-bypass is not feasible,

\footnotetext{
${ }^{15}$ This implies that if $\underline{s} \geq 0.306$, then $\alpha^{*}<\alpha^{w}$ always.

${ }^{16}$ For the entire range of parameter values (which includes both linear and two-part tariff structures) the average $s\left(\alpha^{*}\right)$ when the equilibrium level of access is suboptimally high is 0.13 , whereas when the equilibrium level of access is suboptimally low, it is 0.63 .
} 
the equilibrium per-unit access charge is either $\widehat{r}$ or $\overline{\bar{r}}$. Since $\overline{\bar{r}} \geq \bar{r}$, whenever the per-unit access charge is determined by $\widehat{r}$ (with the outside option), the same access price would apply in the absence of the outside option. Moreover, in such cases, the access level set by the incumbent (given that it does not deny access) would be the same as in our benchmark model. This is simply because the entrant's opportunity cost of obtaining access from the incumbent (i.e., $V$ ) does not depend on the level of access when $\widehat{r} \leq \bar{r}$, and hence, the optimal access level is the same regardless of the presence of an outside option. (See Appendix D.)

However, in other cases (i.e., if $\bar{r}<\widehat{r} \leq \overline{\bar{r}}$ or $\widehat{r}>\overline{\bar{r}}$ ), this is no longer true. For a given level of access, the incumbent sets a higher per-unit price when the entrant has no outside option than when it has one, as $\overline{\bar{r}} \geq \bar{r}$ implies $\min \{\widehat{r}, \overline{\bar{r}}\}>\bar{r}$. Therefore, the equilibrium level of access might be different with the full-bypass option and with no full-bypass option.

Finally, we ran our simulations with the same functional forms and parameter values specified in Section 3 to test whether there is foreclosure in equilibrium when full-bypass is not viable. Our simulations confirm that there is no foreclosure in equilibrium. This is because, with a two-part tariff schedule the incumbent-at the worse-can replicate the monopoly profits. Our simulations show that this is also true when the equilibrium tariff is linear. ${ }^{17}$

\subsection{Asymmetric marginal costs}

In this section, we assume that the incumbent's downstream marginal cost for providing broadband services is equal to $c$ and that the entrant's marginal cost is equal to $c+\theta$, where $\theta$ can be either positive or negative.

If the equilibrium tariff schedule is two-part, one can show that the per-unit access price is decreasing with $\theta$. That is, the incumbent provides access at a lower unit-price to a relatively less efficient entrant.

If the incumbent provides access to a level $\alpha$ of its infrastructure and charges $\widehat{r}$, the marginal effect of $\alpha$ on $\Pi_{1}(\alpha)$ is given by equation (1). Since $\partial s / \partial \alpha$ is negative and $\partial\left(\pi_{1}+\pi_{2}\right) / \partial s$ is positive, then the higher $\partial\left(\pi_{1}+\pi_{2}\right) / \partial s$, the greater $\alpha^{*}$ is. We find that $\partial^{2}\left(\pi_{1}+\pi_{2}\right) / \partial s \partial \theta \leq 0$, which implies that the industry profits become less sensitive to product differentiation when the entrant's cost inefficiency $(\theta)$ increases for a given $c$. The reason is that any efficiency difference between the incumbent and the entrant mitigates the effect of product differentiation which is determined by

\footnotetext{
${ }^{17}$ Note that, we do not restrict the tariff schedule to be linear or fixed, in which cases one could observe foreclosure.
} 
the incumbent's access strategy. Hence, the incumbent provides access at a higher level when the entrant is less efficient.

Proposition 4 The larger the entrant's cost inefficiency (relative to the incumbent), $\theta$, the higher the level of access, $\alpha^{*}$.

Proof. See Appendix E.

For the cases where the equilibrium tariff is linear, using the same functional specifications and parameter values, we ran simulations and verified that a marginal increase in the entrant's marginal cost leads to a higher equilibrium level of access. ${ }^{18}$

\subsection{Cournot competition}

In this section, we compare our results of the benchmark model to those that would be obtained under Cournot competition. When the equilibrium is characterized with a two-part tariff, we find that the per-unit access price under Cournot competition is

$$
\widehat{r}^{C}=\frac{(a-c)(1-s)(1+s)^{2}}{2\left(1+6 s-3 s^{2}\right)} .
$$

For a given $s$, the per-unit price is lower under Cournot competition than under Bertrand competition. The intuition follows that of Arya et al. (2008); under Bertrand competition, the per-unit price serves as a commitment to compete softly, but this commitment does not work under Cournot competition.

Let $\pi_{i}^{B}$ and $\pi_{i}^{C}$ denote the equilibrium profit of firm $i$ under Bertrand competition and Cournot competition, respectively. Assume that $\Pi_{1}$ is concave in $\alpha$. If the equilibrium under both Bertrand and Cournot competition is characterized by a two-part tariff, then the equilibrium access level is higher under Cournot competition than under Bertrand competition if

$$
\frac{\partial\left(\pi_{1}^{C}+\pi_{2}^{C}\right)}{\partial s}<\frac{\partial\left(\pi_{1}^{B}\left(s, r^{*}(s)\right)+\pi_{2}^{B}\left(s, r^{*}(s)\right)\right)}{\partial s}
$$

The following proposition shows that this is true only for low degrees of differentiation.

Proposition 5 The equilibrium level of access is higher under Cournot competition than under Bertrand competition if $s\left(\alpha^{*}\right)<0.175$ and is lower otherwise.

\footnotetext{
${ }^{18}$ From our benchmark case with symmetric marginal costs, we tested if a marginal increase in the entrant's marginal cost (with a step of $10^{-3}$ ) leads to a higher $\alpha^{*}$.
} 
Proof. We find that

$$
\frac{\partial\left(\pi_{1}^{C}+\pi_{2}^{C}\right)}{\partial s}-\frac{\partial\left(\pi_{1}^{B}+\pi_{2}^{B}\right)}{\partial s}
$$

has the sign of $15 s^{5}-67 s^{4}+110 s^{3}-54 s^{2}-45 s+9$. This polynomial is decreasing in $s$ for $s \in[0,1]$, is negative for $s<0.175$ and is positive otherwise. Therefore, the equilibrium level of access is higher under Cournot for $s<0.175$ and is lower otherwise.

The per-unit access price serves as a better commitment device to soften competition under Bertrand than under Cournot competition. Nevertheless, the profits under Cournot competition are less sensitive to differentiation than they are under Bertrand competition.

\subsection{Cost-based access regulation and free entry (or multiple entrants)}

In the broadband telecommunications market, the conventional wisdom is that a higher level of access (e.g., pure resale) would result in a higher number of entrant firms. In this section, we extend our analysis to multiple entrants, and while doing so, we assume that the access to the incumbent's infrastructure is subject to cost-based regulation $(T=0)$. We compute the free entry equilibrium, and compare how the number of entrant firms change with the access level set by the incumbent.

We consider $N \geq 1$ symmetric entrants, ${ }^{19}$ which means that together with the incumbent $N+1$ firms compete in the market, each of which earn a gross profit of

$$
\pi(N, s)=\frac{(a-c)^{2}[N-(N-1) s] s}{[N-(N-2) s]^{2}(N+1-N s)}
$$

Given that access is provided at level $\alpha$, each entrant makes a net profit of $\pi(N, s(\alpha))-d(\alpha)$. We have

$$
\frac{\partial \pi(N, s)}{\partial N}=-(1-s)(a-c)^{2} s \frac{(1-s)(2 N(1-s)+1+3 s) N+2 s^{2}}{[N-(N-2) s]^{3}(N+1-N s)^{2}}<0,
$$

and hence, the net profit of each firm decreases as the number of entrants increases. Therefore, in the free entry equilibrium, the number of entrants, $N^{*}$, is the maximum integer $N$ such that $\pi(N, s(\alpha)) \geq d(\alpha)$. Ignoring the integer problem, we define the equilibrium number of entrants by

$$
\pi\left(N^{*}, s(\alpha)\right)=d(\alpha)
$$

\footnotetext{
${ }^{19}$ In this section, we only consider symmetric entrants. With asymmetric entrants different strategic concerns may arise. For example, an unregulated incumbent could adopt an exclusive access strategy and provide a higher level of access than it would provide under non-exclusivity, and deter entry if the infrastructure development cost of the next potential entrant in line is sufficiently high.
} 
We now determine the relation between $N^{*}$ and $\alpha$. A higher $\alpha$ has two opposite effects on the equilibrium number of entrants. First, a higher $\alpha$ implies a lower $d(\alpha)$, which leads to a higher $N^{*}$ (due to the cost effect). At the same time, a higher $\alpha$ implies a lower $s(\alpha)$, which leads to a lower $\pi(N, s(\alpha))$, and hence to a lower $N^{*}$ (due to the competition effect). Indeed, we have

$\frac{\partial \pi(N, s)}{\partial s}=\frac{(a-c)^{2} N}{(N+1-N s)^{2}(N-(N-2) s)^{3}}\left[(1+s)(1-s)^{2} N^{2}+(1-s)\left(3 s^{2}+1\right) N+2 s^{3}\right]>0$.

If the competition effect dominates the cost effect, then the equilibrium number of entrants is decreasing with the level of access. Otherwise, it is increasing with the level of access.

As an illustration, consider the same functional specifications as in Section 4, except a slight modification in the investment cost function; $d(\alpha)=\delta\left(1-\alpha^{1 / 2}\right)+f_{0}$, with and $f_{0}=0.004 .^{20}$ The figure below shows the equilibrium number of entrants (defined as the maximum integer $N$ such that $\pi(N, s(\alpha)) \geq d(\alpha))$ as a function of the level of access for $\underline{s}=0.1, \bar{s}=0.9$ and $\delta=0.4$. As the figure shows, the number of entrants varies non-monotonically with the level of access. Starting from no access $(\alpha=0)$, the number of entrants decreases as the level of access increases until a certain level of access $(\alpha=0.4)$ after which the number of entrants increases with the level of access. Note that, in this particular example, there are more competitors in the market when there is pure facility-based competition $(\alpha \approx 0)$ than when there is pure service-based competition $(\alpha \approx 1)$.

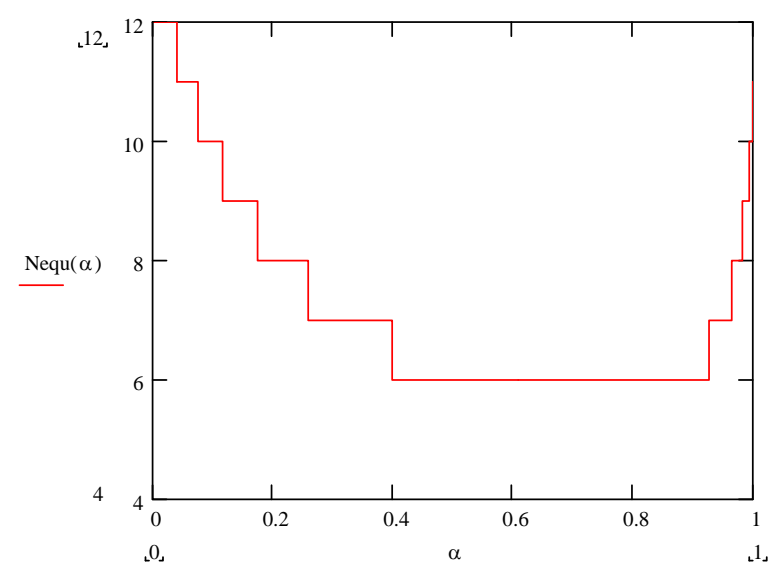

This example shows that in our framework the number of entrants does not necessarily increase with the level of access, which contradicts the conventional wisdom. This is because, though the effect of the level of access on the entry cost is usually well identified (this is the cost effect), the

\footnotetext{
${ }^{20}$ We assume that there is a small fixed cost of entry in addition regardless of the level of access to avoid an infinite number of entrants for $\alpha=1$.
} 
effect of the level of access on differentiation (i.e., the competition effect) is generally not taken into account. When both effects are accounted for, there is a non- monotonic relation between the level of access and the equilibrium number of entrants.

\section{Conclusions}

We have shown that to the extent that infrastructure sharing affects the degree of service differentiation, the incumbent can shape post-entry competition via setting the level of access. Our benchmark model predicts that the equilibrium level of access is suboptimally high if the degree of differentiation is high and it is suboptimally low otherwise.

Factors that alter the sensitivity of the industry profits to the degree of service differentiation (e.g., the type of competition, cost asymmetries in production) also affect the equilibrium level of access, and therefore the degree of infrastructure sharing. In particular, Cournot competition yields a lower equilibrium level of access unless the degree of differentiation is very low. Furthermore, when the incumbent faces a relatively inefficient firm, it sets a higher level of access. Extending our model to allow for free entry (under regulated access), we also show that the equilibrium number of competitors can vary non-monotonically with the level of access.

Although our model provides a framework to study infrastructure sharing by fixed-line incumbent operators, one needs to introduce competing infrastructure owners to study, for example, mobile network operators' incentives to share their infrastructures with virtual mobile network operators. Our theoretical framework can be extended to address these and similar questions. Finally, we assumed that the incumbent has perfect information on both the marginal production and investment costs of the entrant. When this is not true, the incumbent may provide multiple access schemes with multiple levels of access, which could serve as a screening device.

\section{References}

[1] Armstrong, M. (2002). The theory of access pricing and interconnection. In M. E. Cave, S. K. Majumdar, \& I. Vogelsang (Eds.), Handbook of Telecommunications Economics: Vol. 1, structure, regulation and competition, Amsterdam: North-Holland, pp. 295-384.

[2] Arya, A., Mittendorf , B., and Sappington , D. (2008). Outsourcing, vertical integration, and price vs. quantity competition. International Journal of Industrial Organization. Vol. 26, pp. 
$1-16$.

[3] Avenali, A., Matteucci, G., \& Reverberi, P. (2009), Dynamic access pricing and incentives to invest in alternative infrastructures.International Journal of Industrial Organization. Vol. 28(2), pp. 176-190.

[4] Bourreau, M. and Dogan, P. (2006). 'Build-or-Buy' strategies in the local loop. American Economic Review Papers and Proceedings, Vol. 96(2), pp. 72-76.

[5] Bourreau, M. and Dogan, P. (2005). Unbundling the local loop. European Economic Review, Vol. 49, pp.173-199.

[6] Bourreau, M., Hombert, J., Pouyet, J. and Schutz, N. (2009). Upstream Competition Between Vertically Integrated Firms. Mimeo.

[7] Cambini, C. and Jiang, Y. (2009). Broadband investment and regulation: A literature review. Telecommunications Policy. Vol. 33(10-11), pp. 559-574.

[8] Cave, M., (2006). Encouraging infrastructure competition via the ladder of investment. Telecommunications Policy, Vol 30, pp. 223-237.

[9] Crandall, R., Ingraham, A., and Singer, H. (2004). Do unbundling policies discourage CLEC facilities-based investment. The B.E. Journals in Economic Analysis 6 Policy, Manuscript 1136.

[10] Dixit, A., 1979. A Model of Duopoly Suggesting a Theory of Entry Barriers. Bell Journal of Economics, Vol. 10, pp. 20-32.

[11] Friederiszick, H., Grajek, M., and Roller, L.-H. (2008). Analyzing the Relationship between Regulation and Investment in the Telecom Sector. ESMI White Paper No. WP-108-01.

[12] Gayle, P. G. and Weisman, D. L. (2007). Are input prices irrelevant for make-or-buy decisions? Journal of Regulatory Economics, Vol. 32, pp.195-207.

[13] Jorde, T., Sidak, G., and Teece, D. (2000). Innovation, investment and unbundling. Yale Journal on Regulation, Vol. 17(1), pp. 1-37.

[14] Laffont, J.-J., Tirole, J. (2000). Competition in telecommunications, Munich Lectures in Economics. MIT Press, New York. 
[15] Sappington, D. (2005). On the irrelevance of input prices for make-of-buy decisions. American Economic Review, Vol. 95(5), 1631-1638.

[16] Singh, N., Vives, X. (1984). Price and Quantity Competition in a Differentiated Duopoly. RAND Journal of Economics, Vol. 15, pp. 546-554.

[17] Vareda, J. (2007). Unbundling and incumbent investment in quality upgrades and cost reduction. Portuguese Competition Authority. Working Paper No. 526.

[18] Vogelsang, I. (2003). Price regulation of access to telecommunications networks. Journal of Economics Literature, Vol. 41(3), pp. 830-862.

[19] Wallsten, S. and Hausladen, S. (2009). Net neutrality, unbundling and their effects on international investment in next generation networks. Review of Network Economics, Vol. 8(1), pp. 90-112.

[20] Waverman, L., Meschi, M., Reillier, B., and Dasgupta, K. (2007). Access regulation and infrastructure investment in the telecommunications sector: an empirical investigation. Report by LECG Consulting, London, UK. 


\section{Appendix}

\section{A Stage 3 equilibrium profits}

At stage 3 the incumbent and the entrant set prices simultaneously to maximize their profits, $\Pi_{1}=\left(p_{1}-c\right) q_{1}+r q_{2}+f$, and $\Pi_{2}=\left(p_{2}-c-r\right) q_{2}-f$, respectively. Let

$$
\pi_{1}=\left(p_{1}-c\right) q_{1}+r q_{2}
$$

and

$$
\pi_{2}=\left(p_{2}-c-r\right) q_{2}
$$

In equilibrium, we find that

$$
\pi_{1}(s, r)=\frac{[(a-c)(3-s) s+3 r(1-s)][(a-c)(3-s)-(1-s)(2-s) r]}{(1+s)^{2}(3-s)^{2}(2-s)}+r \frac{(3-s)(a-c)-2 r(2-s)}{(1+s)(3-s)(2-s)}
$$

and

$$
\pi_{2}(s, r)=\frac{[(a-c)(3-s)-2 r(2-s))]^{2}}{(1+s)^{2}(3-s)^{2}(2-s)} s
$$

\section{B Proof of Proposition 1}

Proof. The incumbent's problem is

$$
\max _{r, f} \Pi_{1}(\alpha, r, f)=\max _{r, f}\left\{\pi_{1}(s(\alpha), r)+f\right\}
$$

subject to (C1) and (C2). The nondegenerate constraint qualification holds at any candidate solution, as the Jacobian matrix of the constraint functions has rank two. We form the Lagrangian

$$
L\left(r, f, \lambda_{1}, \lambda_{2}\right)=\pi_{1}(s(\alpha), r)+f-\lambda_{1}\left(f-\pi_{2}(s(\alpha), r)+d(\alpha)+(\pi(\bar{s})-d(0))\right)+\lambda_{2} f .
$$

The two first order conditions are

$$
\begin{gathered}
\frac{\partial L}{\partial r}=\frac{\partial}{\partial r}\left(\pi_{1}(s(\alpha), r)+\lambda_{1} \pi_{2}(s(\alpha), r)\right)=0, \\
\frac{\partial L}{\partial f}=1-\lambda_{1}+\lambda_{2}=0,
\end{gathered}
$$


and we have

(a) $\lambda_{1}\left(f-\pi_{2}(s(\alpha), r)+d(\alpha)+(\pi(\bar{s})-d(0))\right)=0, \lambda_{2} f=0$,

(b) $\lambda_{1} \geq 0, \lambda_{2} \geq 0$

(c) $f-\pi_{2}(s(\alpha), r) \leq-d(\alpha)-(\pi(\bar{s})-d(0))$ and $f \geq 0$.

We have $\lambda_{2} f=0$ either because (i) $f=0$, or (ii) $\lambda_{2}=0$.

(i) If $\lambda_{2}=0$, then $\lambda_{1}=1$ (from the second FOC). Since $\lambda_{1}=1$, then $r$ maximizes $\pi_{1}+\pi_{2}$ from the first FOC, and we have necessarily $f=\pi_{2}(s(\alpha), r)+d(\alpha)+(\pi(\bar{s})-d(0))$.

(ii) If $f=0$, then $f=\pi_{2}(s(\alpha), r)+d(\alpha)+(\pi(\bar{s})-d(0))=0$, as $1-\lambda_{1}+\lambda_{2}=0$ and $\lambda_{2} \geq 0$ imply that $\lambda_{1}>0$. Therefore, we have $r=\bar{r}(\alpha)$ and $f=0$.

\section{Proof of Proposition 3}

We have (for $r^{w}=0$ )

$$
w=(a-c)^{2} \frac{2 s+1}{(1+s)^{2}(2-s)} .
$$

We find that

$$
\frac{\partial\left(\pi_{1}\left(s, r^{*}(s)\right)+\pi_{2}\left(s, r^{*}(s)\right)\right)}{\partial s}=2(a-c)^{2} \frac{\left(5 s^{4}-19 s^{2}+36 s^{2}-36 s+18\right)}{(2-s)^{2}\left(5 s^{2}-10 s+9\right)^{2}},
$$

and

$$
\frac{\partial w}{\partial s}=(a-c)^{2} \frac{4 s^{2}-s+1}{(1+s)^{3}(2-s)^{2}}
$$

We find that

$$
\frac{\partial\left(\pi_{1}+\pi_{2}\right)}{\partial s}>\frac{\partial w}{\partial s}
$$

holds if and only if $s>0.306$.

\section{No full-bypass option for the entrant}

If $\bar{\Pi}_{2}<0$, the only possibility of entry is through access to the incumbent's infrastructure. If the incumbent decides to share its infrastructure, it first sets $r$ and $f$ such that its profits are maximized 
for a given $\alpha$, subject to $0 \leq f \leq \pi(s(\alpha))-d(\alpha)$. The inequality on the right-hand side is similar to $(\mathrm{C} 1)$ except that the value of the outside option (i.e., $V$ ) is zero here. Therefore, the analysis is similar to the benchmark analysis. In particular, if $r^{*}=\widehat{r}$ with the outside option, then $r^{*}=\widehat{r}$ also without the outside option. This is because the upper bound on $r$ without the outside option, $\overline{\bar{r}}$, is such that $\overline{\bar{r}}(\alpha) \geq \bar{r}(\alpha)$ for all $\alpha$. Given that the optimal per-unit price is the same with or without the outside option, and given that the incumbent provides access to the entrant, then, the optimal level of access is also the same.

However, since the entrant has no outside option, the incumbent could deter entry by setting $\alpha=0$ (no access). The incumbent decides whether or not to provide access by comparing its monopoly profit if it refuses to provide access, $\pi_{1}^{m}=(a-c)^{2} / 4$, to its equilibrium profit if it provides access, $\Pi_{1}\left(\alpha^{*}\right)$.

\section{E Proof of Proposition 4}

Let

$$
f(\theta, s)=\frac{\partial}{\partial \theta} \frac{\partial\left(\pi_{1}+\pi_{2}\right)}{\partial s}
$$

We find that

$$
\frac{\partial}{\partial \theta} f(\theta, s)=-\frac{4(1-s)\left(5 s^{4}-20 s^{3}+40 s^{2}-40 s+18\right)}{s^{2}(2-s)^{2}\left(5 s^{2}-10 s+9\right)^{2}}
$$

is negative for all $s \in[0,1]$. Therefore, $f(\theta, s)$ is decreasing in $\theta$. Since

$$
f(0, s)=\frac{-2\left(a-c_{1}\right)\left(5 s^{4}-20 s^{3}+41 s^{2}-44 s+22\right)}{(2-s)^{2}\left(5 s^{2}-10 s+9\right)^{2}}
$$

is negative for all $s \in[0,1]$, we have proved that $\partial\left(\pi_{1}+\pi_{2}\right) / \partial s$ is decreasing with $\theta$, which proves that $\alpha^{*}$ is increasing with $\theta$. 